This item was submitted to Loughborough's Research Repository by the author.

Items in Figshare are protected by copyright, with all rights reserved, unless otherwise indicated.

\title{
Electrical method of monitoring percolation and abrasion of conducting spheres due to shear flow of a dense suspension in a narrow gap
}

\section{PLEASE CITE THE PUBLISHED VERSION}

\section{PUBLISHER}

Copyright (1999) American Institute of Physics. This article may be downloaded for personal use only. Any other use requires prior permission of the author and the American Institute of Physics.

\section{VERSION}

VoR (Version of Record)

\section{LICENCE}

CC BY-NC-ND 4.0

\section{REPOSITORY RECORD}

Mannan, Samjid H., David A. Hutt, and David C. Whalley. 2019. "Electrical Method of Monitoring Percolation and Abrasion of Conducting Spheres Due to Shear Flow of a Dense Suspension in a Narrow Gap". figshare. https://hdl.handle.net/2134/4875. 
This item was submitted to Loughborough's Institutional Repository (https://dspace.lboro.ac.uk/) by the author and is made available under the following Creative Commons Licence conditions.

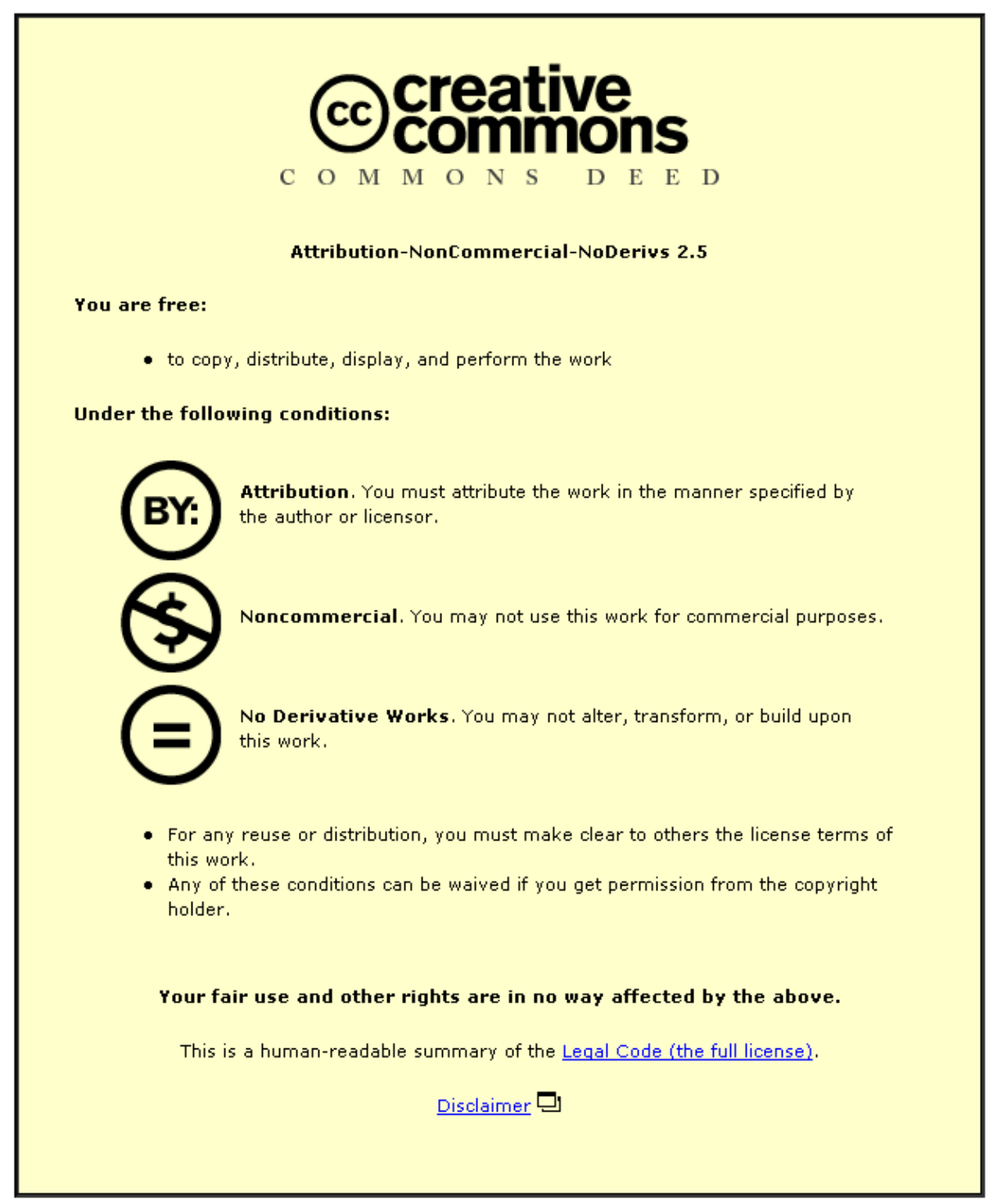

For the full text of this licence, please go to: http://creativecommons.org/licenses/by-nc-nd/2.5/ 


\title{
Electrical method of monitoring percolation and abrasion of conducting spheres due to shear flow of a dense suspension in a narrow gap
}

\author{
S. H. Mannana) \\ Department of Mechanical Engineering, King's College London, London WC2R 2LS, United Kingdom
}

D. A. Hutt and D. C. Whalley

Department of Manufacturing Engineering, Loughborough University, Loughborough LE11 3TU, United Kingdom

(Received 26 April 1999; accepted for publication 12 June 1999)

\begin{abstract}
This letter describes a method for studying the behavior of rigid particles in a dense suspension when they are forced into contact during flow within a narrow gap. The particles form transient percolating networks spanning the boundary walls, and will be crushed together. The method involves measuring the dc electrical resistance across the gap. The suspension (e.g., solder paste) consists of electrically conducting particles suspended in an insulating fluid. The electrical resistance drops when the particles are in contact with each other and the walls, and the insulating films on the surface of the conductors have been broken through. The results show a dramatic change in behavior as the ratio of gap to particle diameter is varied. (C) 1999 American Institute of Physics. [S0003-6951(99)02832-6]
\end{abstract}

Fundamental study of the behavior of the mechanical locking of particles in dense suspensions during shear dates to the work of Bagnold. ${ }^{1}$ In that work, the mechanical transmission of stresses through a percolating particle network was measured by detecting normal stresses on the rheometer walls. The experimental aspects of the work have been updated by several authors ${ }^{2,3}$ as well as by theoretical developments which seek to combine hydrodynamical forces with mechanical stresses caused by direct particle contact. ${ }^{4}$ However, the work presented in this letter differs from earlier studies in that individual jamming events will be monitored (by observing sharp changes in conductance values) as well as the combined effects of thousands of events. This is possible only because of the extreme sensitivity of electrical measurements to the forces acting on the particles. The flows

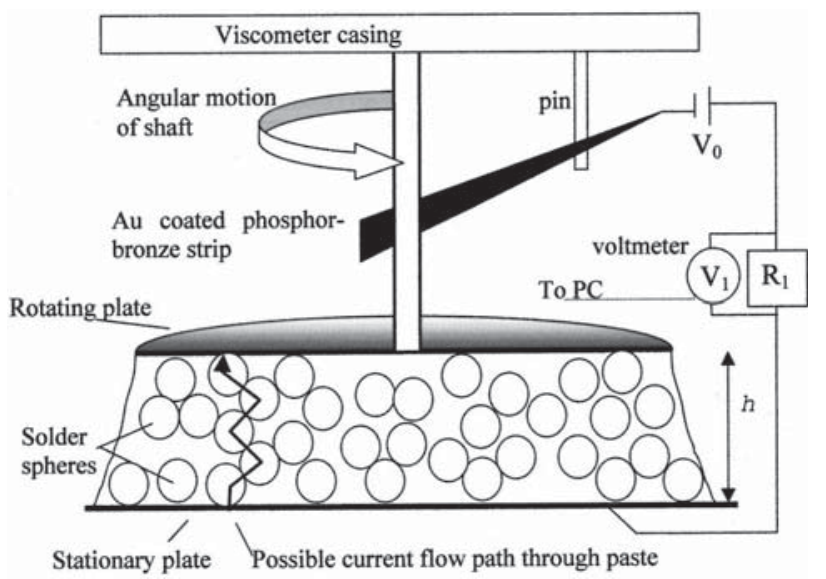

FIG. 1. Cross section of experimental setup (not to scale).

${ }^{a)}$ Electronic mail: samjid.mannan@kcl.ac.uk studied take place in the low Reynold's number regime, in the non-Brownian limit, and with negligible inertial forces acting on the particles.

Particles are jammed against each other when the faster moving particles of one layer are hindered by the slowly moving particles of a neighboring layer. This is responsible for dilatant behavior in the material and normal forces are generated. Occasionally, more severe particle jamming results; particles may become locked together until the pressure buildup behind them forces them to give way. As this occurs, the oxide layers are broken through and electrical pathways are formed between the walls. ${ }^{5}$ Detecting when these occur allows us to determine the frequency at which these blockages occur, the duration of each blockage, and the degree of compression acting on the particles.

It is important to note that this technique can be used to detect individual events that could not be detected by measuring the normal force directly, as the sensitivity of such measurements is far too low. However, these events do have significant implications for the flow behavior of the suspension, and on the condition of the particle and wall surfaces.

Figure 1 shows the modifications made to a parallelplate rheometer (Bohlin Visco 88). This instrument was then used to carry out experiments on samples of solder paste, which consists of solder spheres (occupying 50\% of the volume), suspended in an insulating liquid. The solder particles range in diameter from 10 to $25 \mu \mathrm{m}$, and the outer surfaces

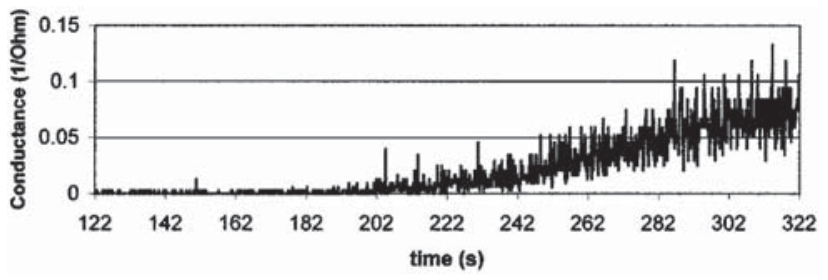

FIG. 2. $h=100 \mu \mathrm{m}$. Plate set into motion at $122 \mathrm{~s}$ 


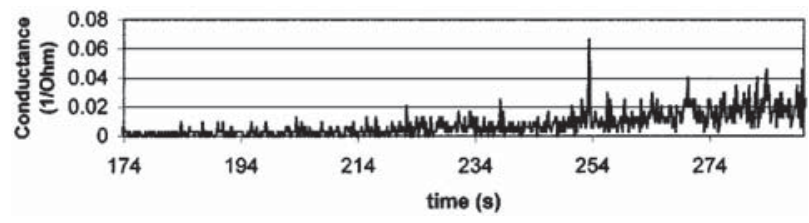

FIG. 3. $h=125 \mu \mathrm{m}$. Plate set into motion at $113 \mathrm{~s}$ (no spikes before $174 \mathrm{~s}$ ).

are covered with a thin layer of metal oxide (mainly $\operatorname{tin}^{6}$ ), which normally prevents conduction unless surfaces rub past each other. In Fig. 1, a phosphor bronze strip was bent between the pin and metal shaft to obtain a pressure contact to the rotating shaft. The level of noise generated by the pressure contact was measured to be small, but electrical noise was picked up from surrounding experiments despite using shielded cables. This noise gave false conductance spikes of up to $0.01 \Omega^{-1}$, even with open-circuit conditions, so only spikes higher than this level are significant. The conductance of the solder paste is given as $1 / R_{\text {paste }}$ where

$$
R_{\text {paste }}=\left(V_{0}-V_{1}\right) R_{1} / V_{1} \text {, }
$$

and $V_{0}$ is set at $35 \mathrm{mV}, V_{1}$ is the voltage measured by the voltmeter, and $R_{1}$ is set at $10 \Omega$. The diameter of the rotating plate was $10 \mathrm{~mm}$, and the surface was stainless steel; this surface was cleaned before every experiment. The bottom conducting surfaces used were $\mathrm{Au}$, solder, and $\mathrm{Cu}$. The graphs shown below were obtained using a solder surface, but the results were similar irrespective of the exact surface used. The angular velocity of the rotating plate was $2.1 \mathrm{rad} / \mathrm{s}$, and the data-sampling rate was $5.7 \mathrm{~Hz}$.

From Figs. 2-4 we deduce that the gap height has a very significant effect on the level of surface abrasion and crushing. With the gap set to $175 \mu \mathrm{m}$, seven times the largest particle diameter $(25 \mu \mathrm{m})$, almost no conduction is observed, while gaps of four and five times the largest particle diameter yield continuous conduction after some initial well-defined

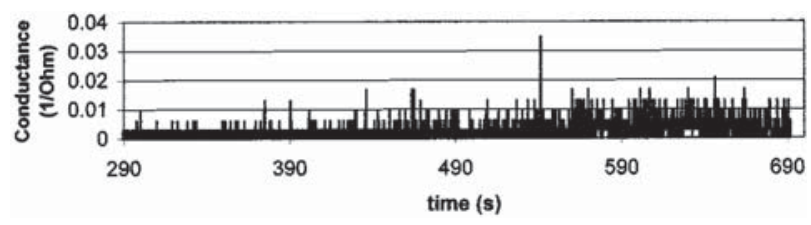

FIG. 4. $h=150 \mu \mathrm{m}$. Plate set into motion at $290 \mathrm{~s}$.

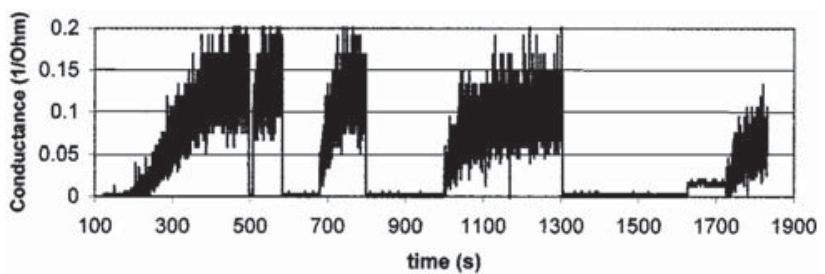

FIG. 5. $h=100 \mu \mathrm{m}$. Plate set into motion at $122 \mathrm{~s}$.

spikes. The increase in conduction with time is seen to be due to the action of continual abrasion of the surfaces due to relative motion, removing oxides.

Figure 5 shows the regeneration of the insulating (probably oxide) layers while the shearing is stopped for periods of 10,100,200, and $400 \mathrm{~s}$; the level of conduction observed when the rotation is restarted is seen to decrease as the idle time is increased. However, the overall trend in conduction is downwards (after the initial increase from zero), possibly due to particle migration out of the gap.

Some trials have also shown spikes occurring at regular intervals, which correspond to the period of rotation of the plate, but this does not occur in the majority of cases (as can be checked by Fourier transforming the data). Similarly, a sharp jump in conduction value is observed in a small number of cases while the plates are stationary (e.g., at $1600 \mathrm{~s}$ in Fig. 5), presumably due to settling or rearrangement of particles. These effects are worthy of further study but do not contradict the central point of this letter, which is that electrical methods are suitable for examining the changes in mechanical forces acting on particles when sheared in narrow gaps of varying sizes.

This work was conducted under U.K. EPSRC Grant No. GR/L61767, and with the help of an industrial consortium of partners including Multicore Solders, Ltd., Celestica Europe, Ltd., Mitel Semiconductor, Ltd., DEK Printing Machines, Ltd., and Matra BAe Dynamics, Ltd.

${ }^{1}$ R. A. Bagnold, Proc. R. Soc. London, Ser. A 225, 49 (1954)

${ }^{2}$ S. B. Savage and S. J. McKeown, J. Fluid Mech. 127, 453 (1983).

${ }^{3}$ D. C.-H. Cheng, Powder Technol. 37, 255 (1984).

${ }^{4}$ P. Mills and P. Snabre, J. Phys. II 5, 1597 (1995)

${ }^{5}$ R. Holm, Electric Contacts: Theory and Application, 4th ed. (Springer, Berlin, 1967).

${ }^{6}$ P. P. Conway and D. J. Williams, in Manufacturing Challenges in Electronic Packaging, edited by Y. C. Lee and W. T. Chen (Chapman and Hall, London, 1998), pp. 82-113. 